\title{
AGILE PROJECT AND PORTFOLIO MANAGEMENT: A SYSTEMATIC LITERATURE REVIEW
}

Frederico Cipriano BATISTA

ISCTE - Instituto Universitário de Lisboa | Portugal

frederico.batista@winning.pt

Leandro Ferreira PEREIRA

Renato Lopes da COSTA

\begin{abstract}
Aims: The application of Agile Methods (AM) in project management has shown great efficiency and remarkable results. However, these methods were born to be applied at team level and not at project portfolio level, where the complexity of managing multiple agile projects and teams leads to several challenges of resource management, priorities and governance model of the project portfolio. The systematic literature review performed in this research aims to identify which practices are the most appropriate to manage the challenges associated with Agile Portfolio Management (APM) and which is the most appropriate context.
\end{abstract}

\section{Methodology / Approach:}

\section{Research Process}

A manual search was performed on B-On, Research Gate, Science Direct and Scopus databases. The research focused on the search and combination of terms and keywords such as "Agile AND Project Portfolio Management", "Scaled-Agile AND Project Portfolio Management", "Agile AND Agile Project Portfolio Management".

\section{Inclusion and exclusion criteria}

Empirical papers published in English language between 2005 and 2020 were included in the B-On, Research Gate, Science Direct and Scopus databases, which are directly related to research issues. The empirical research studies selected were case study, experience report, and systematic review according to the definitions proposed by Tonella, Torchiano \& Du Bois (2007). References from books, theses and workshops, articles written in other language than English and all articles outside the selected timeframe were excluded.

Study selection

The study selection process was inspired by the structure used by Vallon, Estácio, Prikladnicki \& Grechenig (2017), with 6 selection levels.

\section{Data extraction and synthesis}

Data extraction was done by qualitative reading of the selected studies by the first author. To analyse the most referred words in the selected articles and to identify patterns, were collected the most frequent words, bigrams and trigrams of the studies.

Conclusions / Results: The previous research leaded by Dikert et al. (2016), where the success factors and challenges for large-scale transformations were identified, served as inspiration to create the different dimensions of the techniques that were identified. It was also considered the domains of practice that enable agility outside individual projects, identified in the research conducted by Stettina \& Hörz (2015). The dimensions of the two studies mentioned above were considered and techniques and best practices collected in this literature review were classified into 4 APM dimensions: Coordination, Project and resource prioritization, Agility and Change Management. A typification of each technique and best practice was also created where we can typify by: Artifact, Event, Structure, Process, Roles and Principles.

Research implications: This research analysed 28 studies that had identified techniques and best practices to address APM challenges. For APM practitioners, it intends to give an understanding of the most efficient best practices for managing agile portfolios and how to ensure the appropriate conditions for these implementations.

Originality: The existing scientific literature on APM is still very limited and this literature review aims to establish the basis and guide additional empirical studies and contribute to increase scientific studies on APM. The 4 APM dimensions identified in this study represents a new point of view regarding managing multiple agile projects and teams.

KEYWORDS: Agile; Agile Portfolio Management; Scaled Agile.

\section{REFERENCES}

Dikert, K., Paasivaara, M. \& Lassenius, C. (2016). Challenges and success factors in large-scale agile transformations: A systematic literature review. Journal of Systems Software. 119, 87-108.

Paasivaara, M., Lassenius, C. \& Heikkila, V.T. (2012). Inter-team Coordination in Large-Scale Globally Distributed Scrum: Do Scrum-of-Scrums Really Work? Proceedings of the 2012 ACM-IEEE International Symposium 
on Empirical Software Engineering and Measurement Empirical Software Engineering and Measurement.

Stettina, C. J. \& Horz, J. (2015). Agile portfolio management: An empirical perspective on the practice in use. International Journal of Project Management. 33(1), 140-152.

Tonella, P., Torchiano, M., Du Bois, B. (2007). Empirical studies in reverse engineering: state of the art and future trends. Empirical Software Engineering. 12 (5), 551-571.

Vallon, R., Estácio, B., Prikladnicki, R. \& Grechenig, T. (2017). Systematic literature review on agile practices in global software development. Information and Software Technology. 96, 161-180. 